\title{
Human resource challenges in scaling up the response to HIV in Papua New Guinea
}

\author{
John Rule, ${ }^{a}$ Heather Worth, ${ }^{b}$ Graham Roberts ${ }^{a}$ and Richard Taylor ${ }^{a}$ \\ Correspondence to John Rule (e-mail: j.rule@unsw.edu.au).
}

I n Papua New Guinea, an estimated $0.9 \%$ of the adult population is infected with HIV, and the spread of the epidemic is geographically heterogeneous. ${ }^{1}$ The seriousness of the epidemic presents many issues for the government, donors and nongovernmental organizations. One of the greatest challenges of the HIV response is that of human resources. This article highlights human resource issues specific to HIV in Papua New Guinea and raises a series of questions that need to be addressed.

The Australian Agency for International Development (AusAID) Review of HIV Training Programs in Papua New Guinea, conducted in 2009, noted that there had been no assessment of the quality and effectiveness of HIV training programmes or documentation of numbers trained. ${ }^{2}$ The review demonstrated that there are multiple agencies involved at many different levels in the human resource response to HIV, and the review commented on the lack of coordination between agencies. The most significant recommendation was that training programmes needed to be re-oriented so that they are based on a strategic assessment of needs reflecting national and provincial priorities and focusing on new developments in the epidemic.

In 2011, the Independent Review Group on HIV delivered a report to the Papua New Guinea National AIDS Council Secretariat and the National Department of Health $(\mathrm{NDOH})$ indicating that while health service staff in several provinces had maintained HIV service levels in 2010 relative to 2008 and 2009, there were significant human resource concerns. ${ }^{3}$ These included increasing STI and HIV patient loads with static or diminished staffing levels, insufficient space with occupational health risks for staff and patients alike and stock-outs of some drugs and repeated stock-outs of HIV test kits.
Ongoing restructuring of the $\mathrm{NDoH}$ has also meant the loss of key staff and insufficient funds to support supervisory activities. Additionally, there are problems emerging for Papua New Guinea in meeting recurrent costs and absorbing staff positions introduced by Global Fund-supported activities. ${ }^{4}$ The Papua New Guinea 2010 United Nations General Assembly Special Session country progress report indicated that the capacity to deliver prevention of parentto-child transmission (PPTCT) services remains limited. ${ }^{5}$ The report also noted other staffing issues, including a lack of formal training for managers, and a limited understanding of PPTCT and variable interpretations of global PPTCT standards.

The only comprehensive study of the HIV workforce in Papua New Guinea is that of Buchanan-Aruwafu \& Amos. ${ }^{6}$ The study found that half of the 141 health workers sampled had been educated more than 20 years before the baseline, with a quarter of health staff completing their education between 30 and 40 years before. Only a quarter had completed their education in the last eight years. Health staff interviewed reported that they had participated in a variety of courses in the previous year. These courses were stand-alone and not part of an ongoing and nationalized training course. The majority of health workers surveyed reported that the facility in which they worked lacked adequate staff. Many also reported that staff would arrive late for work, and some reported staff being absent for extended periods. Unscheduled staff absences, when there is already inadequate staffing, further contributes to staff frustration, the possibility of facility closure and the inability to provide health services. Facility closures occurred frequently due to shortages of medicine, staffing issues, water problems, criminal activities or tribal fighting.

\footnotetext{
Human Resources for Health Knowledge Hub, School of Public Health and Community Medicine, Faculty of Medicine, University of New South Wales, Sydney, Australia.

School of Public Health and Community Medicine, Faculty of Medicine, University of New South Wales, Sydney, Australia. Submitted: 1 May 2012; Published: 3 September 2012 doi: 10.5365/wpsar.2012.3.2.006
} 
More than half of health workers in the study reported that staff did not receive enough supervision, with only three-fifths reporting that a doctor had visited their facility. While over half of health workers reported that their last supervisory visit was within the last month, a quarter had their last supervisory visit six months before. Two-thirds of health workers reported that they were not satisfied with their working conditions, and three-quarters were frustrated in their work. Not receiving pay on time or not having adequate drugs and medical supplies were identified by health staff as contributing significantly to feeling frustrated at work. Staff also reported that they did not feel safe from contracting HIV.

From the limited amount of available information in relation to the HIV workforce in Papua New Guinea it appears that a major concern is the potential for training recipients to enter the workforce with limited and variable sets of skills and with little likelihood of receiving ongoing support and supervision. There is concern that this can lead to a disintegrated service response and to staff operating with limited effectiveness.

There has been considerable direct investment in HIV workforce training in Papua New Guinea. It is recognized that greater integration of HIV workforce training, with, for example, trainings in Sexually Transmitted Infections Syndromic Management and Adolescent and Sexual Reproductive Health, is required in Papua New Guinea. Indeed, the Papua New Guinea National Health Plan 2011-2020 has the overarching goal of integration of all programmes within a strengthened primary health care framework. ${ }^{7}$

The redistribution of health workforce away from other health priorities toward HIV-programme planning needs to be further examined in Papua New Guinea. This has been noted as occurring in other countries, and with the imperative to continue and extend the provision of HIV-related services, specific tasks have been delegated to less trained staff and sometimes to community members. ${ }^{8,9}$ In some countries the response of taskshifting has been adopted, either formally delegated by policy and supported by task-specific training, or informally by community members taking on new roles. ${ }^{10}$ The potential of such strategies to effectively prevent HIV transmission and to provide treatment and care services for people living with HIV requires investigation in the Papua New Guinea context.

In identifying the HIV workforce policy issues, it is clear that a number of policy options need to be addressed in Papua New Guinea, and these include:

- integration and coordination of national training plan and inputs towards achieving the HIV workforce goals of the Papua New Guinea National Health Plan 2011-2020, ${ }^{7}$ in particular Key Result Area 6, aiming to reduce the burden of communicable diseases;

- agreement on sets of workforce competencies needed for the prevention of HIV transmission and the provision of treatment and care in the cultural contexts of Papua New Guinea;

- assessment of task-shifting as a feasible strategy in the HIV response in Papua New Guinea;

- expansion of infrastructure and services as proposed in the recent Papua New Guinea Global Fund grant, especially those sections of the grant focused on health system strengthening through health workforce development at provincial and district levels;

- strengthening of management systems at the district level to support health workers in the field by ensuring appropriate supervision;

- strengthening of management systems at the national level to ensure that health workers' payments are timely and medical supplies are adequate; and

- coordination of HIV workforce training and management through national, provincial and district-level planning in Papua New Guinea.

There are considerable challenges facing the health workforce in relation to the HIV epidemic in Papua New Guinea. Developing HIV workforce training and competencies as well as improving infrastructure and management systems are just some of the key issues requiring further investigation. 


\section{Conflicts of interest}

None.

Funding

None.

\section{References:}

1. HIV Prevalence: 2009 Estimates. Port Moresby, National AIDS Council Secretariat and National Department of Health, 2010.

2. AusAID, Sanap Wantaim Program. Review of HIV Training Programs in Papua New Guinea. Port Moresby, Australian Agency for International Development, 2009.

3. Independent Review Group on HIV/AIDS. Report from an assessment visit 28 April-13 May 2011. Port Moresby, National AIDS Council Secretariat, 2011 (http://aidsdatahub. org/dmdocuments/Independent Review Group on HIV AIDS_2011_2nd_Mission.pdf, accessed 30 April 2012).

4. Rudge JW et al. Critical interactions between Global Fundsupported programmes and health systems: a case study in Papua New Guinea. Health Policy and Planning, 2010, 25(Suppl 1): i48-52. doi:10.1093/heapol/czq058 pmid:20966110

5. The UNGASS 2010 Country Report Papua New Guinea. Port Moresby, National AIDS Council Secretariat and
Partners, $2011 \quad$ (http://www.unaids.org/en/dataanalysis/ monitoringcountryprogress/progressreports/2010countries/ papuanewguinea_2010_country_progress_report_en.pdf, accessed 30 April 2012).

6. Buchanan-Aruwafu H, Amos A. HIV Prevention in Rural Economic Enclaves: A Health Workers Baseline Survey. Special Publication No. 60. Port Moresby, National Research Institute, 2010 (http:// www.nri.org.pg/publications/Recent\%20Publications/2011\%20 Publications/Health\%20Worker\%20Survey\%20final\%20 301110.pdf, accessed on 30 April 2012).

7. National Department of Health. National Health Plan 2011-2020: Volume 1 Policies and Strategies. Port Moresby, Government of Papua New Guinea, 2010 (http://www.wpro.who.int/countries/ png/PNGNHP_Part1.pdf, accessed 30 April 2012).

8. Bärnighausen $T$, Bloom DE, Humair $S$. Human resources for treating HIV/AIDS: needs, capacities, and gaps. AIDS Patient Care and STDs, 2007, 21:799-812. doi:10.1089/ apc.2007.0193 pmid:17944556

9. Elzinga $\mathrm{G}$ et al., Global Health Workforce Alliance Technical Work Group. Human Resources for Health Implications of Scaling Up For Universal Access to HIV/AIDS Prevention, Treatment, and Care: Ethiopia Rapid Situational Analysis. Geneva, World Health Organization, 2010 (http://www.who.int/workforce alliance/knowledge/publications/Ethiopia_report.pdf, accessed 30 April 2012).

10. Task shifting: rational redistribution of tasks among health workforce teams: global recommendations and guidelines. Geneva, World Health Organization, 2008 (http://www.who.int/healthsystems/TTR-TaskShifting.pdf, accessed 30 April 2012). 